\title{
Pre-storm NmF2 enhancements at middle latitudes: delusion or reality?
}

\author{
A. V. Mikhailov ${ }^{1}$ and L. Perrone ${ }^{2}$ \\ ${ }^{1}$ Institute of Terrestrial Magnetism, Ionosphere and Radio Wave Propagation, Troitsk, Moscow Region 142190, Russia \\ ${ }^{2}$ Istituto Nazionale di Geofisica e Vulcanologia, Via di Vigna Murata 605, Rome 00143, Italy
}

Received: 14 October 2008 - Revised: 28 November 2008 - Accepted: 16 December 2008 - Published: 18 March 2009

\begin{abstract}
A critical analysis of recent publications devoted to the $N m \mathrm{~F} 2$ pre-storm enhancements is performed. There are no convincing arguments that the observed cases of $N m \mathrm{~F} 2$ enhancements at middle and sub-auroral latitudes bear a relation to the following magnetic storms. In all cases considered the $N m \mathrm{~F} 2$ pre-storm enhancements were due to previous geomagnetic storms, moderate auroral activity or they presented the class of positive quiet time events (Qdisturbances). Therefore, it is possible to conclude that there is no such an effect as the pre-storm $N m \mathrm{~F} 2$ enhancement as a phenomenon inalienably related to the following magnetic storm. The observed nighttime $N m \mathrm{~F} 2$ enhancements at subauroral latitudes may result from plasma transfer from the plasma ring area by meridional thermospheric wind. Enhanced plasmaspheric fluxes into the nighttime F2-region resulted from westward substorm-associated electric fields is another possible source of nighttime $N m \mathrm{~F} 2$ enhancements. Daytime positive Q-disturbances occurring under very low geomagnetic activity level may be related to the dayside cusp activity.
\end{abstract}

Keywords. Atmospheric composition and structure (Thermosphere - composition and chemistry) - Ionosphere (Ionosphere-atmosphere interactions; Ionospheric disturbances)

\section{Introduction}

The problem of $N m \mathrm{~F} 2$ pre-storm enhancements comes up from time to time in literature (Danilov et al., 1985; Danilov and Belik, 1992; Danilov, 2001; Kane, 2005; Buresova and

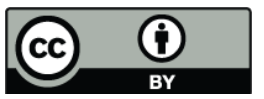

Correspondence to: A. V. Mikhailov (avm71@orc.ru)
Laštovička, 2007, 2008; Liu et al., 2008; Blagoveschensky et al., 2006; Blagoveschensky and Kalishin, 2009). Both the morphology and plausible mechanisms are considered. However the question is not as simple as it might seem. First of all, the very fact of such enhancements' existence should be established in relation to the following geomagnetic disturbances, i.e., are the two phenomena related or is this a coincidence and are the researchers wanting to see this relationship? According to Buresova and Laštovička $(2007,2008)$, only $20-25 \%$ of magnetic storms are accompanied by prestorm $N m \mathrm{~F} 2$ enhancements. What kind of $N m \mathrm{~F} 2$ increase may be considered as a pre-storm enhancement (its magnitude, duration and lead time) should be established. However, all these morphological features have not been specified yet. Moreover, the mechanism of the mid-latitude F2-layer formation is well-established and one should hardly invent new rather vague mechanisms especially to explain this effect (Blagoveschensky and Kalishin, 2009). Side by side with this, one can find quite reasonable suggestions on the mechanisms: variations of zonal electric field $(\boldsymbol{E} \times \boldsymbol{B}$ plasma drift) at low latitudes (Liu et al., 2008), or neutral composition changes due to particle precipitation into the dayside cusp (Danilov et al., 1985; Danilov and Belik, 1992). The latter may be considered as an interesting proposition bearing in mind that such a process is not accompanied by an increase of geomagnetic activity measured in conventional indices and the pre-storm enhancements, in principle, should take place under a low magnetic activity level (see later). Direct CHAMP observations (Lühr al., 2004; Schlegel, 2005) have revealed a pronounced neutral density increase above the dayside cusp. The analysis of DE-2 observations (Prölss, 2006) has shown the electron temperature increase in the vicinity of the dayside cusp manifesting ionization and heating due to particle precipitation into the cusp area. The results of model calculations by Demars and Schunk (2007) indicate an essential neutral temperature increase which is

Published by Copernicus Publications on behalf of the European Geosciences Union. 
required to explain the observed neutral density variations. Therefore, this proposition may open the way for further analyses in this direction.

On the other hand, there exists a class of quiet time F2layer disturbances (Mikhailov et al., 2004) which may play the role of pre-storm enhancements, but they are not related to the following magnetic storms. Therefore, the aims of the paper may be specified as follows: to provide a critical analysis of some results published on this problem and to try to draw a conclusion whether such a phenomenon as a prestorm $N m \mathrm{~F} 2$ enhancement really exists in the mid-latitude F2-region. Possible physical mechanisms of the observed positive $N m \mathrm{~F} 2$ deviations are also discussed.

\section{Analysis of the publications}

As far as we know, the problem of the $N m \mathrm{~F} 2$ pre-storm enhancements has been formulated for the first time by A. Danilov with co-authors (Danilov et al., 1985; Danilov and Belik, 1992; Danilov, 2001). In those papers, the effect was demonstrated by some cases of $f o \mathrm{~F} 2$ enhancement. All the cases were nighttime ones and took place in winter at a sub-auroral station, St. Petersburg $\left(\Phi_{\text {inv }}=55.9^{\circ}\right)$. In further considerations, we will use both $N m \mathrm{~F} 2$ and $f o \mathrm{~F} 2$ parameters which are related by a well-know expression. Before starting our analysis, a general assumption should be made. In the ideal case, a pre-storm $f_{o} \mathrm{~F} 2$ enhancement should precede the magnetic storm onset (SC moment) and take place within a reasonable time interval (say, within $24 \mathrm{~h}$ before the SC) and should develop under quiet geomagnetic conditions. If an observed $f_{o} \mathrm{~F} 2$ increase does not correspond to these requirements, there is no reason to consider it as a pre-storm enhancement: it may be attributed to quite different processes. In our analysis we base it on the conventional indices: 3-h ap, AE, $D_{s t}$, and PCN. Quiet time conditions correspond to $\mathrm{AE}<100 \mathrm{nT}$ and $\mathrm{PCN}<2$. All the periods with $f o \mathrm{~F} 2$ enhancements referred to in the papers in question were reanalyzed. Some differences with the original results in $f o \mathrm{~F} 2$ variations may arise from different medians used. Instead of monthly median, we use a 27-day running median centered for the day in question (Mikhailov et al., 2004), but when $f o F 2$ deviations are large enough, this difference in medians is not important.

Let us briefly consider the periods from Danilov (2001) and Danilov and Belik (1992) papers.

1 January 1978. That was a quiet period without any geomagnetic storms, but with splashes of AE-index up to $400 \mathrm{nT}$ and PCN $>2$ during the 1-2 January 1978 night. Daytime $f o \mathrm{~F} 2$ values exhibited a stable positive effect during 4 days (30 December 1977-2 January 1978). The nighttime foF2 increase on 1-2 January 1978 may be attributed to the moderate auroral activity according to AE- index variations.

1 March 1981. The entire period 24 February 1981-6 March 1981 was disturbed with the PCN index often ex- ceeding 2, $D_{s t}<-30 \mathrm{nT}$. Splashes of AE index up to $550 \mathrm{nT}$ took place during the 28 February-1 March 1981 night. The $f o \mathrm{~F} 2$ peak coincides exactly in time with the increased $\mathrm{AE}$ indexes.

14 February 1980. During the 13-14 February 1980 night the $B_{z}$ component was southward providing favorable conditions for a geomagnetic storm development. Although, during the 13-14 February 1980 night AE indices were $<100 \mathrm{nT}$, the period of a moderate $f o \mathrm{~F} 2$ increase was very close to SC observed at 03:00 UT on 14 February 1980. Therefore, the observed $f o \mathrm{~F} 2$ increase may be considered as a reaction to the storm onset.

12 December 1981. A well-pronounced $f o \mathrm{~F} 2$ increase took place during the whole 11-12 December 1981 night. During this night, $\mathrm{AE}=100-200 \mathrm{nT}$ and $\mathrm{SC}$ took place around 04:00 UT on 12 December 1981. Formally this case looks like a "clear" one. However, similar large $f o \mathrm{~F} 2$ enhancements took place during the 9-10 December 1981 and 13-14 December 1981 nights which hardly can be related to the magnetic storm in question. The entire period 9-12 December 1981 was characterized by moderately enhanced auroral activity with $\mathrm{AE}=100-300 \mathrm{nT}$ and this can explain the elevated $f o \mathrm{~F} 2$ values (see Discussion).

29 December 1981. A well-pronounced foF 2 increase took place from the evening hours till the midnight of 28 29 December 1981. The previous daytime 12:00-17:00 UT period was characterized by enhanced auroral activity with $\mathrm{AE}=170-480 \mathrm{nT}$ and $\mathrm{PCN}>2$ and this should change the thermospheric neutral composition (see Discussion). Moreover, according to $D_{s t}$-index variations a positive excursion (SC) was observed at 08:00-11:00 UT, so the evening $f o \mathrm{~F} 2$ increase took place during the main phase of the storm.

9 January 1983. A pronounced $f \circ \mathrm{F} 2$ increase took place from the evening until midnight on 8-9 January 1983. Positive excursion (SC) of $D_{s t}$ was observed at 13:00-16:00 UT followed by an increase in the auroral activity with $\mathrm{AE}=106-$ $422 \mathrm{nT}$ at 16:00-18:00 UT. Therefore, the $f \circ \mathrm{F} 2$ increase is the reaction to the enhanced auroral activity.

1 March 1983. A very moderate $f o \mathrm{~F} 2$ increase took place during the evening hours on 28 February 1983, but this period coincides with an enhanced auroral activity: $\mathrm{AE}$ indices were up to $330 \mathrm{nT}$ and $\mathrm{PCN}>2$. Similar $f o \mathrm{~F} 2$ enhancement took place during the previous evening.

Summarizing the results on the periods considered by Danilov, one may draw the following conclusions. All the observed $f o \mathrm{~F} 2$ enhancements can be related with the following: (i) moderate auroral activity with $\mathrm{AE}=200-400 \mathrm{nT}$; (ii) a reaction to the SC; (iii) the $f o \mathrm{~F} 2$ enhancements developed under low geomagnetic activity and similar $f o \mathrm{~F} 2$ increases took place for adjacent dates. An essential moment is that St. Petersburg is a sub-auroral station with $\Phi_{\text {inv }}=55.9^{\circ}$ and all the events considered took place during nighttime hours. According to Sagalin and Smiddy (1974) the equatorial boundary of the plasma ring with irregular ionospheric structure, due to soft electron precipitation, is located at $\Phi_{\text {inv }}=58-62^{\circ}$ 
during nighttime hours. Therefore, St. Petersburg is located very close (4 degrees southward on average) to the zone with enhanced and irregular F2-layer ionization. During nighttime the meridional thermospheric wind $V n x$ is equatorward with a velocity of $\sim 100 \mathrm{~m} / \mathrm{s}$ (Hedin, 1991; Buonsanto and Witasse, 1999). This takes less than $1.5 \mathrm{~h}$ for plasma to be transferred from the place of its production to the latitude of St. Petersburg. During nighttime hours, the e-fold time with respect to plasma recombination is much larger than $1.5 \mathrm{~h}$ (Ivanov-Kholodny and Mikhailov, 1986). Therefore, this plasma can be observed at the location of St. Petersburg. Moderately enhanced auroral activity only helps the situation when the plasma ring shifts southward (Yudovich, 1965; Andrews and Thomas, 1969) and the intensity of ionization increases (e.g. Sato and Colin, 1969). Therefore, the analyzed cases of nighttime $f_{o} \mathrm{~F} 2$ enhancements at St. Petersburg can be explained without any relationship to the following magnetic storms.

Another mechanism which may be efficient at the latitude of St. Petersburg during nighttime hours, is plasma compression in the magnetic tubes of force by westward substormassociated electric fields and dumping plasma into the nighttime F2-region (see Discussion). According to Davis et al. (1979) nighttime F2-region electron density enhancements have a maximum near $\Phi=55^{\circ}$ due to latitudinal dependence of the magnetic tube electron content. Magnetic tubes with $L>3$ are only partly filled with plasma due to long time of recovery after geomagnetic disturbances (Carpenter and Park, 1973; Krinberg and Tashilin, 1984).

Next step in this direction was undertaken by Kane (2005) who considered three periods with very large magnetic storms: 28-31 October 2003, 19-22 November 2003, and 13-14 March 1989. He found strong positive effects in $f o \mathrm{~F} 2$ within the $24 \mathrm{~h}$ period before the SC. Based on these three events, he suggests considering, not less than such pre-storm $f o \mathrm{~F} 2$ enhancements as precursors for the geomagnetic disturbances. Later this "idea" was taken up by Blagoveschensky et al. (2006).

28 October 2003. A large positive $f o \mathrm{~F} 2$ enhancement took place during daytime hours. That was a disturbed day and the analysis of his period, see later, in connection with the Buresova and Laštovička $(2007,2008)$ results.

19 November 2003. The auroral activity was elevated for the entire day with daily average $\mathrm{AE}=238 \mathrm{nT}$ and splashes of $\mathrm{AE}$ indices up to $533 \mathrm{nT}$.

12 March 1989. The auroral activity was elevated for the whole day with daily average $\mathrm{AE}=299 \mathrm{nT}$ and splashes of $\mathrm{AE}$ indices up to $1060 \mathrm{nT}$.

Therefore, the three pre-storm periods were disturbed with high enough levels of the auroral activity and the observed $f o \mathrm{~F} 2$ enhancements were due to this activity. The effects of the elevated auroral activity on $N m \mathrm{~F} 2$ variations at middle latitudes are considered later. Whether such pre-storm auroral activity is related to the following magnetic storms is a question which is beyond the scope of this paper. Many ex-

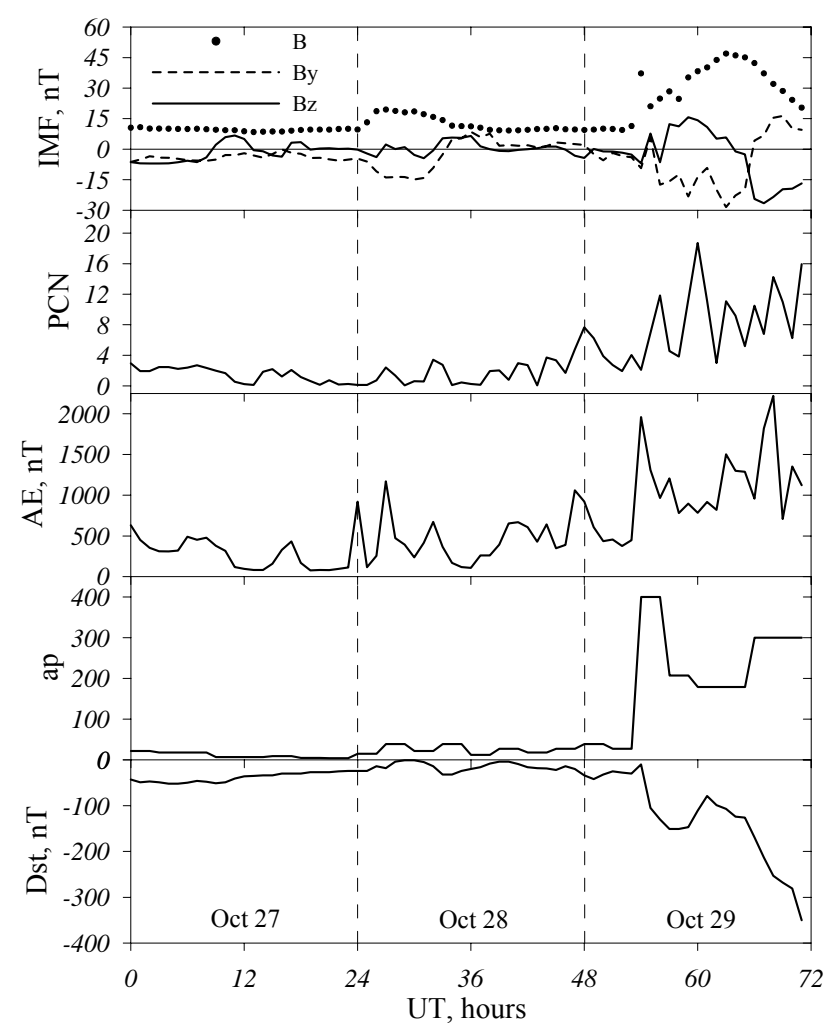

Fig. 1. Helio-geophysical parameter variations for the 27-29 October 2003 period.

amples of isolated magnetic storms can be found which are not preceded by any pronounced auroral activity.

More careful analysis has been performed by Buresova and Laštovička $(2007,2008)$, who analyzed 65 strong geomagnetic storms over the 1995-2005 period using midlatitude worldwide ionosonde observations. They have found the $f o \mathrm{~F} 2$ pre-storm enhancements for 15 events in Europe. No effects have been revealed in the F1- and E-regions and the pre-storm electron density increases were found to be confined to the F2-region only. A longitudinal effect in the $f o \mathrm{~F} 2$ pre-storm occurrence has been also analyzed. All the periods are listed in the paper and this allowed us to reanalyze them.

Their Fig. 1, given as the largest pre-storm enhancement case of 1995-2005, cannot be considered as a successful example. The entire period preceding the 29 October 2003 event was disturbed and the authors themselves stressed this in the paper, but this fact did not stop them.

The geophysical parameter variations characterizing the period in question are given in Fig. 1.

Two substorms took place during 27 October 2003 and 28 October 2003 and PCN was $>2$ for the entire period. The auroral activity was elevated for the whole day of 28 October 2003 with large splashes of AE index (Figs. 1 and 2). The splash of the auroral activity around 08:00 UT (Fig. 2, 


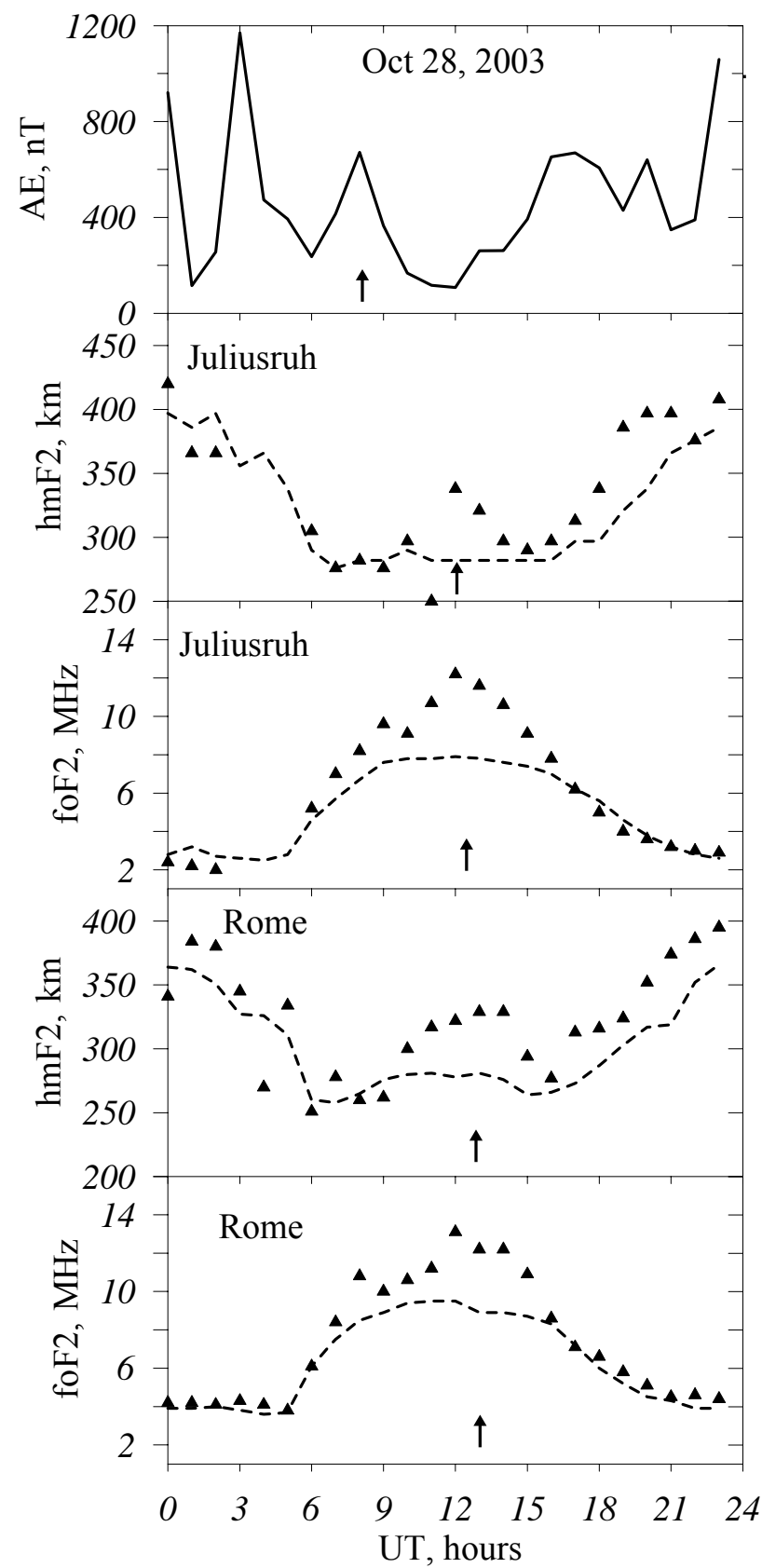

Fig. 2. Observed variations of AE-index, $h m \mathrm{~F} 2$, and $f o \mathrm{~F} 2$ at Juliusruh and Rome on 28 October 2003. The TAD was launched by the upsurge of the auroral activity around 08:00 UT and its passage (arrows) is seen in $h m \mathrm{~F} 2$ and $N m \mathrm{~F} 2$ variations at the two stations. Dashes - median values.

top panel) produced a TAD whose passage is clearly seen in $h m \mathrm{~F} 2$ and $N m \mathrm{~F} 2$ variations at Juliusruh around 12:00 UT and later at Rome around 13:00 UT (Fig. 2). An uplift of the midlatitude F2-layer under sunlit conditions always results in an $N m \mathrm{~F} 2$ increase clearly manifested at Juliusruh and Rome as well as at Slough (their Fig. 1). Therefore, the observed foF2 increase on 28 October 2003 has a clear explanation which is not directly related to the future magnetic storm on 29 October 2003.

The authors have not detected any pre-storm enhancements in the E-region and on this basis they concluded that the pre-storm $f o \mathrm{~F} 2$ enhancements presented a special class of events different from positive Q-disturbances, which according to Mikhailov et al. (2004) present quiet-time F2-layer perturbations not related to geomagnetic activity. However, their analysis was not accurate enough. The method how one can observe the synchronism in $N m \mathrm{~F} 2$ and $N m \mathrm{E}$ variations is described by Mikhailov et al. (2007). Due to the formation mechanisms of the mid-latitude daytime F2- and E-regions, the in-phase $N m \mathrm{~F} 2$ and $N m \mathrm{E}$ variations can be observed only during daytime hours, but the authors did not pay any attention to this important point considering all LT hours and found no coherence, naturally. Moreover, such delicate analysis (due to small $N m \mathrm{E}$ variations) needs special methods (see Mikhailov et al., 2007), which the authors have not applied during their consideration.

We have reanalyzed the 15 periods listed in the paper and added about 20 similar cases on Slough, Juliusruh, Lycksele, and St. Petersburg stations from our data base with quiet-time F2-layer disturbances (Q-disturbances). The selection procedure was arranged to find a daytime positive Q-disturbance followed by a magnetic storm within a 24-h time interval and the storm time period should include at least one ap- $3 \mathrm{~h}$ value $\geq 50$. In the framework of our approach to the analysis of Qdisturbances (Mikhailov et al., 2004), a 27-day foF2 running median, centered for the day in question rather than usual monthly median, is used. On one hand, a 27-day running median looks more natural as this period equals to one solar rotation, on the other hand, this saves us from large and unreal disturbance effects in the beginning and in the end of a month as well as at the junction of two months especially during the equinoctial periods when changes in the thermosphere and ionosphere are very fast. Therefore, some differences with the results based on monthly medians may take place.

The analysis of the selected periods has shown that positive Q-disturbances usually appear as a group of successive (2-6) days. In our selection procedure, this succession is ended by a magnetic storm. Two examples of such successions are given in Figs. 3 and 4 for Lycksele on 4 7 November 1983 (positive daytime and negative nighttime deviations) and for St. Petersburg on 4-7 May 1968 with both daytime and nighttime positive $\Delta N m \mathrm{~F} 2$ deviations. In both cases, the days preceding the magnetic storm were quiet with daily $A_{p} \leq 7$ (see also AE-index variations). All the days in the successions exhibit positive $\Delta N m \mathrm{~F} 2$ deviations during daytime hours. The last days before the storm onset demonstrate exactly the same type of $N m \mathrm{~F} 2$ variations as the 2-3 previous days in the successions. This indicates that such daily $N m \mathrm{~F} 2$ variations (including the pre-storm day) have nothing to do with the following magnetic storm. In the case 


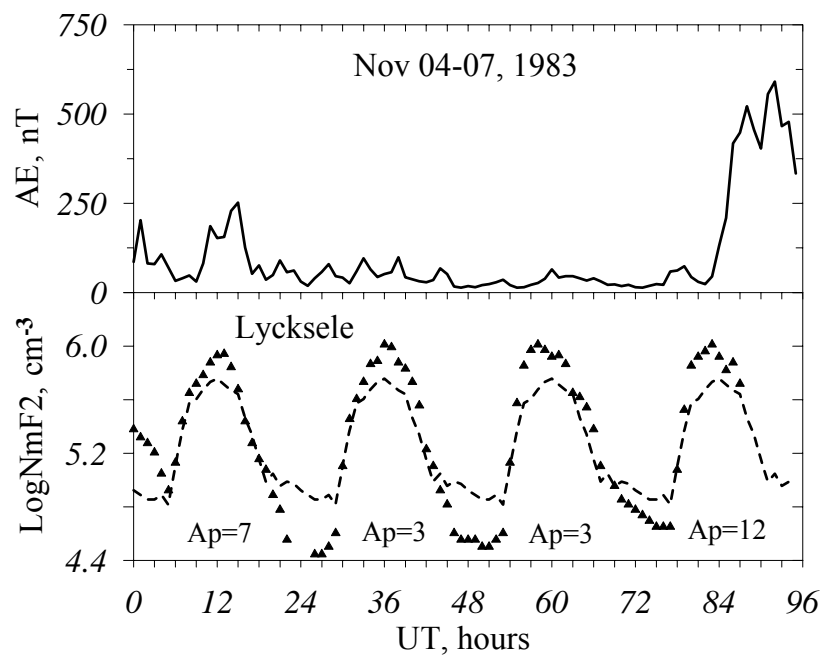

Fig. 3. A 4-day succession of daytime positive and nighttime negative $N m \mathrm{~F} 2$ disturbances under low or slightly elevated auroral activity. Daily $A_{p}$ indices are also given in the lower panel. Note that the pre-storm $N m \mathrm{~F} 2$ daytime enhancement on 7 November 1983 looks absolutely the same as for the previous days.

of 4-7 May 1968 (Fig. 4), the magnetic storm started in the daytime LT sector and this resulted in a positive storm phase, so called positive $\mathrm{NmF} 2$ disturbance of type II (Zevakina and Kiseleva, 1978). However, this effect has quite a different formation mechanism and is not related to the question considered.

We have analyzed such successions for the periods listed in the paper by Buresova and Laštovička (2008) as well as for the extended list of dates. In accordance to our method, only daytime (11:00-14:00) LT hours were analyzed. For both selections, it was found that relative deviations $\delta=N m \mathrm{E}_{\text {obs }} / N m \mathrm{E}_{\text {med }}>1$ (i.e. $N m \mathrm{E}$ are higher than the median) at a confidence level $>95 \%$ according to Student criterion. We have also calculated the correlation coefficient between $\delta N m \mathrm{~F} 2$ and $\delta N m \mathrm{E}$ for the 15 periods listed in the paper by Buresova and Laštovička (2008). We took 1-3 days from each period with positive $\delta N m \mathrm{~F} 2$ deviations. As in our earlier analysis (Mikhailov et al., 2007), the correlation between $\delta N m \mathrm{~F} 2$ and $\delta N m \mathrm{E}$ was found to exist although the coefficient $r=0.32$ is not high, but it is significant at least at the $90 \%$ confidence level, according to Fisher Fcriterion. Therefore, there is a synchronism in $N m \mathrm{~F} 2$ and $N m \mathrm{E}$ variations and we may conclude that such days with positive $\Delta N m \mathrm{~F} 2$ daytime deviations belong to the positive Q-disturbance events (Mikhailov et al., 2004, 2007), i.e. they are not related to the following magnetic storms. Of course, quiet periods end sooner or later by magnetic storms and one of the Q-disturbance days may turn out to be the last in the succession, but this is just a random coincidence.

It should be stressed that, unlike the 28 October 2003 case, the majority of 15 selected periods in the Buresova and

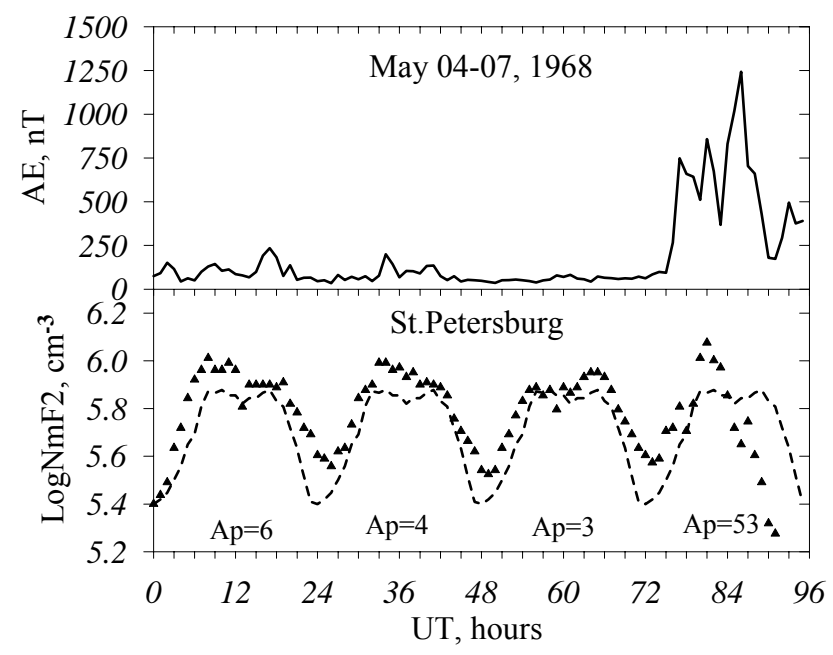

Fig. 4. A 3-day succession of daytime and nighttime positive $N m \mathrm{~F} 2$ disturbances under low or slightly elevated auroral activity. Daily $A_{p}$ indices are also given in the lower panel. Note that the pre-storm nighttime $N m \mathrm{~F} 2$ enhancement on 6 May 1968 looks the same as for the previous days. The daytime $N m \mathrm{~F} 2$ upsurge after the storm SC on 7 May 1968 is a typical of positive storm phase $(\mathrm{NmF} 2$ positive disturbance of type II).

Laštovička (2008) paper were really quiet before the storm onset and they exhibit the $N m \mathrm{~F} 2$ variations similar to those given in Figs. 3, 4. The other question, what did the authors understand when speaking about the $f o \mathrm{~F} 2$ pre-storm enhancement, the entire positively disturbed day (night) with $\delta f o \mathrm{~F} 2>20 \%$, or a splash of such magnitude in diurnal $f o \mathrm{~F} 2$ variations? The $f_{o} \mathrm{~F} 2$ enhancement should wittingly be before the SC and not to coincide with it, but it is hard to tell what is the pre-storm enhancement in the case of $f o \mathrm{~F} 2$ variations similar to those given in Figs. 3, 4.

Another result of the Buresova and Laštovička (2008) analysis is that $N m \mathrm{~F} 2$ enhancements are not accompanied (as a systematic phenomenon) by $\mathrm{Ne}$ enhancements in the F1-region. As earlier with the 28 October 2003 case, their Fig. 3 (22 July 2004) which illustrates this result, is also not successful. On one hand, the top (12:00 UT) and the bottom (14:00 UT) panels clearly show the electron density increase both in the E- and F1-regions at Chilton which is contrary to what the paper says. The middle panel of their Fig. 3 (13:00 UT) is a classical illustration of TAD passage with a corresponding $\mathrm{Ne}(\mathrm{h})$ profile deformation. The SC occurred at 10:36 UT on 22 July 2004 and it was followed by the auroral activity increase around 11:00 UT (Fig. 5). This splash of AE launched the TAD whose passage is seen at Chilton around 13:00 UT (their Fig. 3) and later at Rome (Fig. 5).

The formation mechanisms of the daytime F1- and F2regions are closely related via neutral composition, the scheme of photo-chemical processes being practically the same. Therefore, if the dynamics are not too strong like we have in the case of TAD passage, then one should expect 


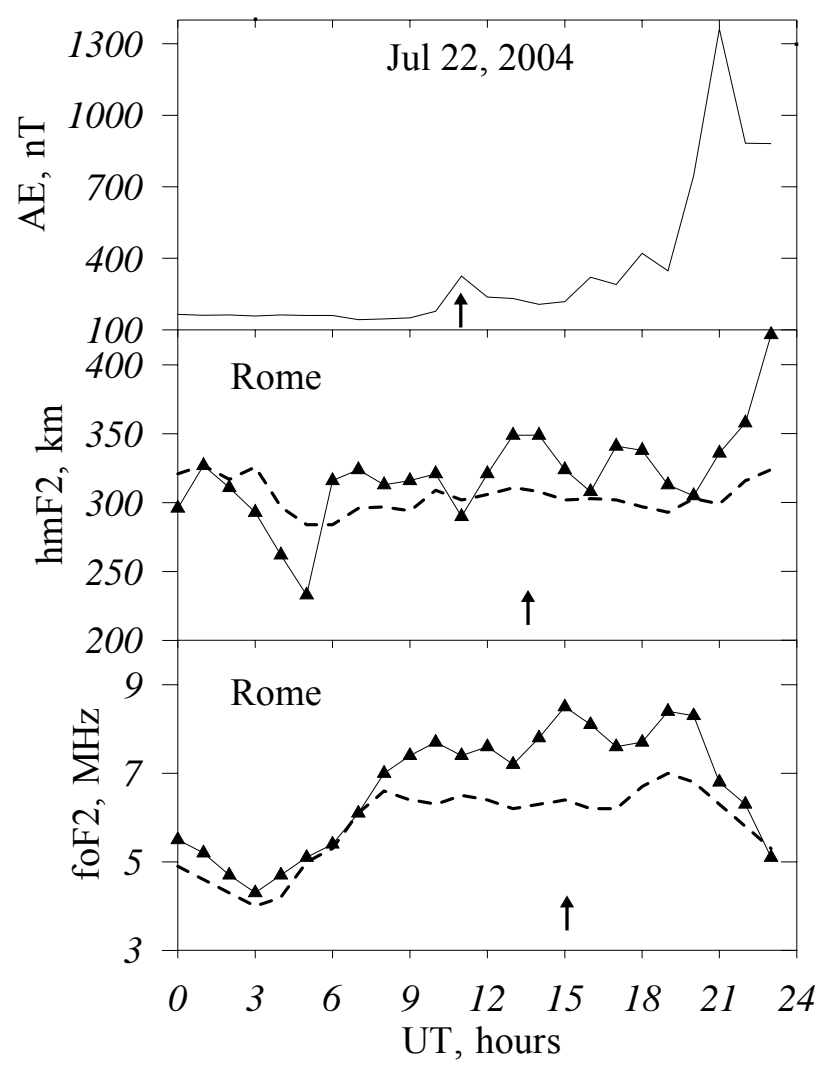

Fig. 5. Observed variations of $\mathrm{AE}-\mathrm{index}, h m \mathrm{~F} 2$, and $f o \mathrm{~F} 2$ at Rome on 22 July 2004. The TAD was launched by the upsurge of the auroral activity around 11:00 UT and its passage (arrows) is seen in $h m \mathrm{~F} 2$ and $N m \mathrm{~F} 2$ variations at Rome around 14:00-15:00 UT. Dashes - median values.

in-phase variations of electron concentration in the two ionospheric regions during daytime hours. This takes place even under disturbed conditions as it was shown by Mikhailov and Schlegel (2003) who analyzed ISR observations. Indeed, positive $\mathrm{NeF} 1$ effects in the F1-region are much less than in the F2-region due to a strong compensating role of molecule ions (Mikhailov and Schlegel, 2003), but basically the sign of $\mathrm{NeF} 1$ changes is controlled by $\left[\mathrm{O}^{+}\right]$variations and this provides the synchronism in $N e \mathrm{~F} 1$ and $N m \mathrm{~F} 2$ variations.

\section{Discussion}

The undertaken analysis has shown that there are no convincing arguments that the observed cases of $N m \mathrm{~F} 2$ prestorm enhancements bear a relation to the following magnetic storms. In all cases considered either the $N m \mathrm{~F} 2$ enhancements were related to moderate auroral activity or similar $N m \mathrm{~F} 2$ enhancements took place during some previous days and such type of $N m \mathrm{~F} 2$ variations have nothing to do with the following magnetic storms. Therefore, it is possible to conclude - there is no such an effect as the pre- storm $N m \mathrm{~F} 2$ enhancement as a phenomenon absolutely related to the following magnetic storm, to say nothing of using such enhancements as a precursor for the following magnetic storms (Kane, 2005; Blagoveschensky et al., 2006).

It may seem that a moderate auroral activity characterized by $\mathrm{AE}=200-400 \mathrm{nT}$ is not sufficient to produce the observed F2-layer positive effects, as many cases of $N m \mathrm{~F} 2$ enhancements considered in the referred papers took place under such conditions, but this is a delusion. The F2-layer positive storm effect is mainly a phenomenon related to substorm activity. This peculiarity was mentioned many years ago by Zevakina and Kiseleva (1978) who found that positive disturbances were more frequent at low and moderate geomagnetic activity with $10<\sum K_{p}<20, \mathrm{AE}_{\max }=200$ $400 \mathrm{n} T, D_{s t}=10-30 \mathrm{nT}$. Similar conclusions were obtained by Zevakina and Hill (1978) who analyzed F2-layer storms at the low-latitude station San Jose where positive disturbances dominate. Only 25 ionospheric disturbances of 125 analyzed were accompanied by magnetic storms. They concluded that "pure" positive ionospheric F2-layer disturbances (not associated with the magnetic ones) exhibited the same variations as the disturbances during geomagnetic storms but only with less amplitude. The same conclusion was made by Park (1974). The analysis by Zevakina and Hill (1978) has shown that all "pure" ionospheric disturbances were associated with weak magnetospheric activity related to a sequence of small substorms, i.e. with low/moderate auroral activity. However, it should be stressed that apart from such types of positive $f o \mathrm{~F} 2$ disturbances, there exist a class of positive Qdisturbances which take place under quiet geomagnetic conditions (Mikhailov et al., 2004).

Zevakina and Kiseleva (1978) were also the first who revealed F2-layer positive disturbances of two types. Type I is referred to those disturbances which are followed by quiet ionospheric conditions. After the active period of such disturbances, enhanced $f o \mathrm{~F} 2$ are observed for the whole day and the active period is repeated in $24 \mathrm{~h}$ with decreased $\delta f o \mathrm{~F} 2 \mathrm{val}-$ ues. Positive disturbances of type II are followed by negative F2-layer storms. The disturbances of type II are shorter than of type I, but their amplitude is larger. Disturbances of type II are accompanied by larger $h m \mathrm{~F} 2$ increases. Actually positive disturbances of type II present the first phase of a two-phase (positive/negative) ionospheric disturbance (see an example in Fig. 4). Some of these peculiarities in the positive storms occurrence were observed later by Tsagouri et al. (2000) and Belehaki and Tsagouri (2002). These morphological differences indicate that the two types of positive disturbances belong to different classes of events and have different formation mechanisms. Positive disturbances of type II occur during sunlit hours and they are due to TADs passage (see later). Long-duration positive disturbances (type I) take place during both daytime and nighttime. They are related mostly to atomic oxygen abundance increase during daytime hours (Mikhailov et al., 2007) and to a plasmaspheric influx during nighttime (Mikhailov et al., 2000b). 
Some comments may be pertinent in relation with the discussed mechanisms. The so called meteorological control of the ionosphere is widely discussed in literature. Although this impact from below is still considered as a reason to explain at least some types of the F2-layer disturbances and this is a work for future, our analysis of Q-disturbances has shown that the main morphological features can be explained in the framework of the contemporary understanding of the thermosphere-ionosphere interaction. That is, the sources of the considered Q-disturbances are located in the thermosphere itself. It should be mentioned that Rishbeth (2006) has also expressed a restrained optimism with regard to the F-region - lower atmosphere links.

Let us analyze the most typical $N m \mathrm{~F} 2$ enhancement cases starting our consideration with daytime mid-latitude conditions. Upsurges of the auroral activity similar to 28 October 2003 (Fig. 2) or 22 July 2004 (Fig. 5) produce TADs moving towards the equator. Apart from the deformation of the $\mathrm{Ne}(\mathrm{h})$ profile as a whole, the equatorward wind in such TADs shifts the F2-layer to higher altitudes with a higher production/loss ratio resulting in an $N m \mathrm{~F} 2$ increase. This is a well-known mechanism of the F2-layer positive storm effect (Prölss, 1993, 1995; Bauske and Prölss, 1997). This type of positive disturbances may be attributed to the type II (Zevakina and Kiseleva, 1978).

Whether such increases of the auroral activity are related to the following magnetic storms, this is a question, but according to Zevakina and Hill (1978) only $20 \%$ of the analyzed F2-layer positive disturbances were accompanied by magnetic storms. This coincides with the estimation (20$25 \%$ ) given by Buresova and Laštovička (2007).

The other situation arises with the positive long-duration F2-layer disturbances, positive Q-disturbances belonging to the same class of the F2-layer perturbations (Mikhailov et al., 2007).

As it was noted earlier, some of the events analyzed by Buresova and Laštovička $(2007,2008)$ belong to this type of the F2-layer disturbances. They are related to slightly enhanced auroral activity when the solar-driven thermospheric poleward wind is damped and this stimulates neutral gas downwelling which increases the atomic oxygen abundance in the thermosphere at sub-auroral and middle latitudes. This was shown, for instance, by Rishbeth (1998, his Fig. 3).

The damped poleward neutral wind reduces the downward plasma drift in the daytime F2-region. Both the atomic oxygen abundance increase and the downward plasma drift decrease result in the $N m \mathrm{~F} 2$ increase during sunlit hours. Such an example is given in Fig. 3. Under low $\left(A_{p}=3-7\right)$ geomagnetic activity, we have positive $\triangle N m \mathrm{~F} 2$ deviations during daytime hours. It may be pertinent to note that according to Burke et al. (2007), significant energy can be deposited in the ionosphere without corresponding magnetic perturbations on the ground. Therefore, low levels of geomagnetic activity measured in conventional magnetic indices may not adequately present a real situation in the ionosphere. This is especially valid when we consider the effects related to the dayside cusp.

A possible relationship of the F2-layer pre-storm enhancements with the dayside cusp activity has been proposed for the first time by A. Danilov with co-authors (Danilov et al., 1985; Danilov and Belik, 1992). This seems to be an interesting idea, bearing in mind that particle precipitation into the cusp produces both ionization (Prölss, 2006) and the thermosphere heating (Lühr et al., 2004; Schlegel et al., 2005; Demars and Schunk, 2007) without any geomagnetic effects. Therefore, some of the F2-layer Q-disturbances may be well related to the dayside cusp activity. Unfortunately, the mechanism mentioned in the first publications by A. Danilov looks pretty vague for the following reasons: the thermospheric heating in the cusp area implies upwelling of neutral gas which results in a decrease of the $\mathrm{O} / \mathrm{N}_{2}$ ratio while positive disturbances need an increase of this ratio. A direct transfer of fresh ionization from the dayside cusp to the nighttime F2-region (all their positive disturbance cases are nighttime ones) over the whole polar cap is impossible due to large time of such transfer. Moreover, according to DE-2 observations in general a decrease in the electron density takes place at the dayside cusp area (Prölss, 2006). This electron density decrease is explainable under the $\mathrm{O} / \mathrm{N}_{2}$ ratio decrease due to neutral gas upwelling.

Therefore, how F2-layer positive disturbances could be related to the dayside cusp activity is not clear. However the very idea of the dayside cusp involvement in the process of the positive disturbances formation proposed by A. Danilov seems to be correct. Here we have the situation similar to slightly elevated auroral activity which was considered earlier. The heated thermosphere above the dayside cusp changes pressure gradients and damps the solar-driven poleward wind stimulating neutral gas downwelling by this way at sub-auroral and middle latitudes. The latter, as it was shown by Rishbeth (1998, his Fig. 3), increases the atomic oxygen abundance in the thermosphere. The $\mathrm{O} / \mathrm{N}_{2}$ ratio increase, along with the downward plasma drift decrease (due to the poleward $V n x$ decrease), provide the $N m \mathrm{~F} 2$ increase during sunlit hours. Therefore, daytime long-duration F2layer positive disturbances observed under very quiet geomagnetic conditions (positive Q-disturbances in Figs. 3, 4) may be related to the dayside cusp activity. An additional analysis is needed to specify the required geophysical conditions when the dayside cusp is efficient to produce such type of F2-layer disturbances.

Speaking about the successions of positive Qdisturbances, it may be interesting to discuss the following: a continuous day-to-day increase in $f o \mathrm{~F} 2$ which is well seen if the quiet-time period is long enough. Such an example is shown in Fig. 6 for the 16-25 September 1958 period at Lycksele. A succession of 8 quiet days is confined on both sides by magnetic storms. A continuous $f o \mathrm{~F} 2$ increase starts from 18 September 1958 and peaks on 22 September 1958. Then the auroral activity started to increase (seen in 


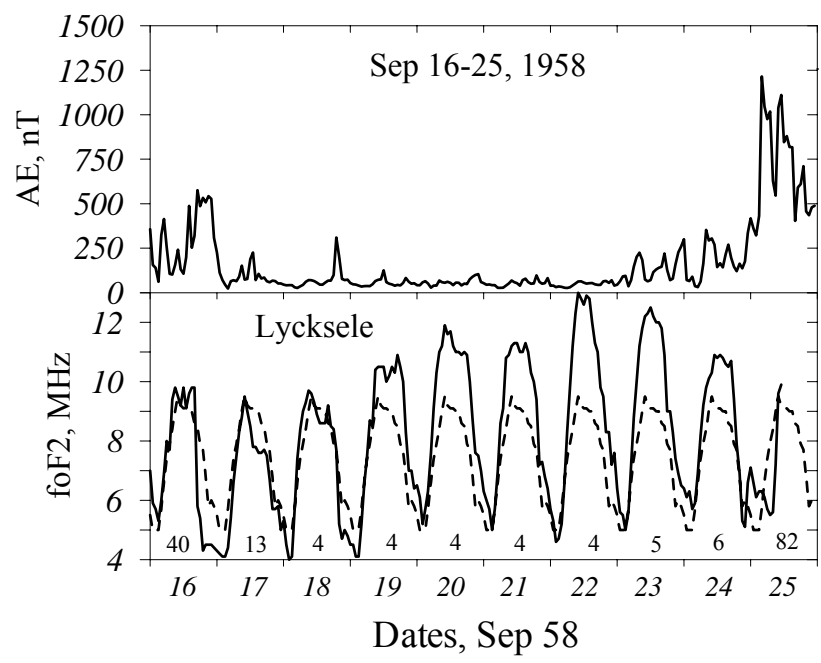

Fig. 6. Observed variations of $\mathrm{AE}$-index and $f o \mathrm{~F} 2$ at Lycksele during the 16-25 September 1958 period. Note a continuous increase of $f o \mathrm{~F} 2$ daytime values until September 22 as a result of the magnetic tube of force refilling by plasma from the daytime F2-region. Figures in the bottom panel - daily $A_{p}$ indices. Dashes - median foF 2 values.

AE indices, but only slightly in $A_{p}$ ) during two days, on the third day a new magnetic storm has started. It is interesting to note that even a slight increase in the auroral activity up to $\mathrm{AE}=200-250 \mathrm{nT}$ on 23-24 September 1958 has stopped the process and $f o \mathrm{~F} 2$ started to decrease. If the magnetic storm started two days earlier on 23 September 1958, we would have a very pronounced "pre-storm" $f_{o} \mathrm{~F} 2$ enhancement in terms of the Buresova and Laštovička (2008) paper.

This day-to-day $N m \mathrm{~F} 2$ increase reflects the refilling process of the depleted magnetic tube of force with plasma from daytime F2-layer (Park, 1970; Krinberg and Taschilin, 1984). The characteristic time of the refilling process for the tube at Lycksele ( $\mathrm{L}=4.4)$ is about 50 days (Krinberg and Taschilin, 1984). Such a tube is never completely filled as magnetic storms depleting it occur more often. The effect of the empty tube is clearly seen for the first three nights following the magnetic storm (Fig. 6). The depleted tube cannot supply a sufficient influx of $\mathrm{O}^{+}$ions into the nighttime F2-region and $N m \mathrm{~F} 2$ values are below the median level. The same effect is seen in Fig. 3 for the 4-6 November 1983 period at Lycksele, but not at St. Petersburg for the 4-7 May 1968 period (Fig. 4). On one hand, a pretty long period preceding the 4-7 May 1968 event was relatively quiet without magnetic storms, therefore the tube was relatively filled. On the other hand, the sunset in May at the latitude of St. Petersburg is later in time than at Lycksele in November and this provides larger $N m \mathrm{~F} 2$ values in the course of the night.

The formation mechanism of the nighttime mid-latitude F2-region includes three factors: the initial starting $N m \mathrm{~F} 2$ value at the sunset, the equtorward thermospheric wind $V n x$, and the plasmaspheric flux of $\mathrm{O}^{+}$ions into the $\mathrm{F} 2$-region (Ivanov-Kholodny and Mikhailov, 1986). The meridional wind only uplifts F2-layer from the fast recombination area providing, in the way, the maintenance of nighttime $\mathrm{NmF} 2$ values at a sufficient level. Large sunset $N m \mathrm{~F} 2$ values may be conserved by this process for many nighttime hours due to a large e-fold time with respect to recombination (Fig. 4). But such types of $N m \mathrm{~F} 2$ variations may hardly be considered as an "enhancement". Therefore, the only way to produce a nighttime $N m \mathrm{~F} 2$ enhancement is to increase the plasma influx from the plasmasphere. This is a well-know problem which has been investigated for many years using worldwide $N m \mathrm{~F} 2$ and TEC observations. The analysis of this nighttime phenomenon and the discussion of its formation mechanism can be found in (Mikhailov et al., 2000a, b, and references therein). The increase of the plasmaspheric flux producing the nighttime $\mathrm{NmF} 2$ enhancement may be stimulated by westward electric field compressing plasma in the magnetic tubes of force and dumping it into the F2-region. This idea has been proposed by Park $(1971,1973)$ who used whistler observations and revealed the depletion of plasmaspheric tubes presumably by westward substorm-associated electric fields. Later this mechanism was confirmed by direct Millstone Hill ISR observations (Mikhailov and Förster, 1999). Therefore, the "pre-storm" nighttime $N m \mathrm{~F} 2$ enhancements occurring under moderate auroral activity may be well due to this mechanism. But it should be stressed that nighttime $N m \mathrm{~F} 2$ enhancements at middle and sub-auroral latitudes is a common phenomenon reflected even in monthly $N m \mathrm{~F} 2$ medians and, therefore, by no means related to geomagnetic storms.

The analysis by Buresova and Laštovička (2008) has shown that $N m \mathrm{~F} 2$ pre-storm enhancement is not a global effect, but is confined to a longitudinal sector although a wide one. This is not a surprising result, which just reflects the difference in formation mechanisms of daytime and nighttime mid-latitude F2-region. For instance, TADs originated from splashes of the auroral activity to produce $N m \mathrm{~F} 2$ increases in the sunlit F2-region, but only $h m \mathrm{~F} 2$ increases during nighttime hours without noticeable changes in $N m \mathrm{~F} 2$. The latter is due to the absence of direct photo-ionization during the night and the F2-layer is uplifted from the fast recombination area by strong equatorward thermospheric wind $V n x$, therefore some movements of the F2-layer in height has small effect in $N m \mathrm{~F} 2$.

The mechanism of nighttime $N m \mathrm{~F} 2$ enhancements may be related either to direct plasma transfer from the auroral oval to the sub-auroral stations by the equatorward $V n x$, or to plasma influx into nighttime F2-region from the plasmasphere. Both processes are inefficient during daytime hours as $V n x$ is poleward and the rate of plasma influx is much less the rate of direct photo-ionization. Therefore, one should not expect simultaneous occurrence of $N m \mathrm{~F} 2$ enhancements in daytime and nighttime LT sectors as it was noted by $\mathrm{Bu}-$ resova and Laštovička (2008). 


\section{Conclusions}

The results of our analysis may be summarized as follows:

1. There are no convincing arguments that the observed cases of $N m \mathrm{~F} 2$ pre-storm enhancements at middle and sub-auroral latitudes considered by other researchers bear a relation to the following magnetic storms. In all cases considered either the $N m \mathrm{~F} 2$ enhancements were due to moderate auroral activity or similar $N m \mathrm{~F} 2$ enhancements took place during some previous days presenting the class of positive Q-disturbance events. Therefore, it is possible to conclude that there is no such an effect as the pre-storm $N m \mathrm{~F} 2$ enhancement as a phenomenon inalienably related to the following magnetic storm.

2. Nighttime $N m \mathrm{~F} 2$ enhancements observed at sub-auroral latitudes under moderate auroral activity can be related to the plasma transfer from the plasma ring area by meridional equatorward wind. Similar $N m \mathrm{~F} 2$ enhancements in the mid-latitude nighttime F2-region may be due to enhanced plasmaspheric fluxes resulted from westward substorm-associated electric fields. Such nighttime $N m \mathrm{~F} 2$ enhancement is a frequently observed phenomenon which is by no means related to geomagnetic storms.

3. Daytime short and pronounced $N m \mathrm{~F} 2$ enhancements are due to TAD passage related to splashes of the auroral activity. At present there are no indications whether such auroral activity increases are related to the following magnetic storms.

4. Long-duration positive Q-disturbances appear as a succession of days with similar $N m \mathrm{~F} 2$ diurnal variations. Such a succession may be cut by a magnetic storm at any moment, but the last day before the storm belongs to the succession and has nothing to do with the following magnetic storms.

5. Positive Q-disturbances occurring under very low geomagnetic activity level need a special mechanism for their explanation. The dayside cusp proposed by A. Danilov as an alternative channel for the F2-layer disturbances formation may help explain the occurrence of this type of the F2-layer positive perturbations. The mechanism includes damping of the background solardriven thermospheric circulation with corresponding neutral gas downweling at middle and sub-auroral latitudes.

Acknowledgements. This work was in part supported by the Russian Foundation for Basic Research under Grant 06-05-64227. The authors are also grateful to A. Danilov for careful reading the paper and some advice on improving language.

Topical Editor M. Pinnock thanks one anonymous referee for her/his help in evaluating this paper.

\section{References}

Andrews, M. K. and Thomas, J. O.: Electron density distribution above the winter pole, Nature, 5577, 223-227, 1969.

Bauske, R. and Prölss, G. W.: Modeling the ionospheric response to traveling atmospheric disturbances, J. Geophys. Res., 102, 14555-14562, 1997.

Belehaki, A. and Tsagouri, I.: On the occurrence of storm-induced nighttime ionization enhancements at ionospheric middle latitudes, J. Geophys. Res., 107, 1209, doi:10.1029/2001JA005029, 2002.

Blagoveschensky, D. V., MacDougall, J. W., and Piatkova, A. V.: Ionospheric effects preceding the October 2003 Halloween storm, J. Atmos. Solar-Terr. Phys., 68, 821-831, 2006.

Blagoveschensky, D. V. and Kalishin, A. S.: A mechanism of the ionosphere critical frequency increase before a sub-storm onset, Geomag. i Aeronom., 49(N2), accepted, 2009.

Buonsanto, M. J. and Witasse, O. G.: An updated climatology of thermospheric neutral winds and $\mathrm{F}$ region ion drifts above Millstone Hill, J. Geophys. Res., 104, 24675-24687, 1999.

Buresova, D. and Laštovička, J.: Pre-storm enhancements of $f_{o} \mathrm{~F} 2$ above Europe, Avd. Space Res., 39, 1298-1303, 2007.

Buresova, D. and Laštovička, J.: Pre-stormelectron density enhancements at middle latitudes, J. Atmos. Solar-Terr. Phys., 70, 1848-1855, 2008.

Burke, W. J., Huang, C. Y., Marcos, F. A., and Wise, J. O.: Interplanetary control of thermospheric densities during large magnetic storms, J. Atmos. Solar-Terr. Phys., 69, 279-287, 2007.

Carpenter, D. L. and Park, C. G.: On what ionospheric workers should know about the plasmapause-plasmasphere, Rev. Geophys. Space Phys., 11, 133-154, 1973.

Danilov, A. D.: F2-region response to geomagnetic disturbances, J. Atmos. Solar-Terr. Phys., 63, 441-449, 2001.

Danilov, A. D., Belik, L. D., and Mirmovich, E. G.: On a possible nature of positive phase of the ionospheric storms, Geomag. i Aeronom., 25, 768-772, 1985 (in Russian).

Danilov, A. D. and Belik, L. D.: Thermospheric composition and the positive phase of an ionospheric storm, Adv. Space Res., 10, 257-260, 1992.

Davies, K., Anderson, D. N., Paul, A. K., Degenhardt, W., Hartman, G. K., and Leitinger, R.: Nighttime increase in total electron content observed with the ATS 6 radio beacon, J. Geophys. Res., 84, 1536-1542, 1979.

Demars, H. G. and Schunk, R. W.: Thermospheric response to ion heating in the dayside cusp, J. Atmos. Solar-Terr. Phys. 69, 649$660,2007$.

Hedin, A. E., Biondi, M. A., Burnside, R. G., Hernandez, G., Johnson, R. M., Killeen, T. L., Mazaudier, C., Meriwether, J. W., Salah, J. E., Sica, R. J., Smith, R. W., Spencer, N. W., Wickwar, V. B., and Virdi, T. S.: Revised global model of thermosphere winds using satellite and ground-based observations, J. Geophys. Res., 96(A5), 7657-7688, 1991.

Ivanov-Kholodny, G. S. and Mikhailov, A. V.: The prediction of ionospheric conditions, Reidel, Dordrecht, 1986.

Kane, R. P.: Ionospheric $f o F 2$ anomalies during some intense geomagnetic storms, Ann. Geophys., 23, 2487-2499, 2005, http://www.ann-geophys.net/23/2487/2005/.

Krinberg, I. A. and Taschilin, A. V.: Ionosphere and plasmasphere, Nauka, Moscow, 1984.

Liu, L., Wan, W., Zhang, M.-L., Zhao, B., and Ning, 
B.: Prestorm enhancements in $N m \mathrm{~F} 2$ and total electron content at low latitudes, J. Geophys. Res., 113, A02311, doi:10.1029/2007JA012832, 2008.

Lühr, H., Rother, M., Köhler, W., Ritter, P., and Grünwaldt, L.: Thermospheric up-welling in the cusp region: evidence from CHAMP observations, Geophys. Res. Lett., 31, L06805, doi:10.1029/2003GL0119314, 2004.

Mikhailov, A. V. and Förster, M.: Some F2-layer effects during the January 06-11, 1997 CEDAR storm period as observed with the Millstone Hill incoherent scatter facility, J. Atmos. Solar-Terr. Phys., 61, 249-261, 1999.

Mikhailov, A. V., Leschinskaya, T. Yu., and Förster, M.: Morphology of $N m \mathrm{~F} 2$ nighttime increases in the Eurasian sector, Ann. Geophys., 18, 618-628, 2000a, http://www.ann-geophys.net/18/618/2000/.

Mikhailov, A. V., Förster, M., and Leschinskaya, T. Y.: On the mechanism of the post-midnight winter $N m \mathrm{~F} 2$ enhancements: dependence on solar activity, Ann. Geophys., 18, 1422-1434, 2000b, http://www.ann-geophys.net/18/1422/2000/.

Mikhailov, A. V. and Schlegel, K.: Geomagnetic storm effects at F1-layer heights from incoherent scatter observations, Ann. Geophys., 21, 583-596, 2003, http://www.ann-geophys.net/21/583/2003/.

Mikhailov, A. V., Depueva, A. H., and Leschinskaya, T. Yu.: Morphology of quiet time F2-layer disturbances: High and lower latitudes, Int. J. Geomag. Aeronom., 1-14, GI1006, doi:10.1029/2003GI000058, 2004.

Mikhailov, A. V., Depuev, V. H., and Depueva, A. H.: Synchronous $N m \mathrm{~F} 2$ and $N m \mathrm{E}$ daytime variations as a key to the mechanism of quiet-time F2-layer disturbances, Ann. Geophys., 25, 483-493, 2007, http://www.ann-geophys.net/25/483/2007/.

Park, C. G.: Whistler observations of the interchange of ionization between the ionosphere and the protonosphere, J. Geophys. Res., 75, 4249-4260, 1970.

Park, C. G.: Westward electric fields as the cause of nighttime enhancements in electron concentrations in midlatitude $F$ region, J. Geophys. Res., 76, 4560-4568, 1971.

Park, C. G.: Whistler observations of the depletion of the plasmasphere during magnetospheric substorm, J. Geophys. Res., 78, 672-683, 1973.

Park, C. G.: A morphlogical study of substorm-associated disturbances in the ionosphere, J. Geophys. Res., 79, 2821-2827, 1974.
Prölss, G. W.: On explaining the local time variation of ionospheric storm effects, Ann. Geophysicae, 11, 1-9, 1993.

Prölss, G. W.: Ionospheric F-region storms, Handbook of Atmospheric Electrodynamics, vol. 2, edited by: Volland, H., CRC Press/Boca Raton, pp. 195-248, 1995.

Prölss, G. W.: Electron temperature enhancement beneath the magnetospheric cusp, J. Geophys. Res., 111, A07304, doi:10.1029/2006JA011618, 2006.

Rishbeth, H.: How the thermospheric circulation affects the ionospheric F2-layer, J. Atmos. Solar-Terr. Phys., 60, 1385-1402, 1998.

Rishbeth, H.: F-region links with the lower atmosphere?, J. Atmos. Solar-Terr. Phys., 68, 469-478, 2006.

Sagalin, R. C. and Smiddy, M.: High latitude irregularities in the topside ionosphere based on ISIS-1 thermal ion probe data, J. Geophys. Res., 79, 4252-4260, 1974.

Sato, T. and Colin, L.: Morphology of electron concentration enhancement at height of 1000 kilometers at polar latitudes, J. Geophys. Res., 74, 2193-2207, 1969.

Schlegel, K., Lühr, H., St.-Maurice, J.-P., Crowley, G., and Hackert, C.: Thermospheric density structures over the polar regions observed with CHAMP, Ann. Geophys., 23, 1659-1672, 2005, http://www.ann-geophys.net/23/1659/2005/.

Tsagouri, I. and Belehaki, A., Moraitis, G., and Mavromichalaki, H.: Positive and negative ionospheric disturbances at middle latitudes during geomagnetic storms, Geophys. Res. Lett. 27, 35793582, 2000.

Yudovich, L. A.: The location of the equatorial boundary of abnormal ionization occurrence depending on planetary magnetic activity, Geomag. i Aeronom., 1113-1114, 1965 (in Russian).

Zevakina, R. A. and Hill, H.: Variations of F-region at low latitudes during magnetospheric storms, In: The diagnostics and modeling of the ionospheric disturbances, Nauka, Moscow, 168-175, 1978 (in Russian).

Zevakina, R. A. and Kiseleva, M. V.: F2-region parameter variations during positive disturbances related to phenomena in the magnetosphere and interplanetary medium, in: The diagnostics and modelling of the ionospheric disturbances, Nauka, Moscow, 151-167, 1978 (in Russian). 